\title{
Oridonin Loaded Solid Lipid Nanoparticles Enhanced Antitumor Activity in MCF-7 Cells
}

\author{
Lu Wang, ${ }^{1}$ Shengpeng Wang, ${ }^{1}$ Ruie Chen, ${ }^{1}$ Yanping Wang, ${ }^{2} \mathrm{Hui} \mathrm{Li,}{ }^{2}$ \\ Yitao Wang, ${ }^{1}$ and Meiwan Chen ${ }^{1}$ \\ ${ }^{1}$ State Key Laboratory of Quality Research in Chinese Medicine, Institute of Chinese Medical Sciences, \\ University of Macau, Macau 999078, China \\ ${ }^{2}$ Institute of Chinese Materia Medica, Chinese Academy of Chinese Medical Sciences, Beijing 100700, China \\ Correspondence should be addressed to Hui Li; lihuiyiren@163.com and Meiwan Chen; mwchen@umac.mo
}

Received 20 November 2013; Revised 14 February 2014; Accepted 14 February 2014; Published 31 March 2014

Academic Editor: Mustafa O. Guler

Copyright (C) $2014 \mathrm{Lu}$ Wang et al. This is an open access article distributed under the Creative Commons Attribution License, which permits unrestricted use, distribution, and reproduction in any medium, provided the original work is properly cited.

\begin{abstract}
Oridonin (ORI), a famous diterpenoid from Chinese herbal medicine, has drawn rising attention for its remarkable apoptosis and autophagy-inducing activity in human cancer therapy, while clinical application of ORI is limited by its strong hydrophobicity and rapid plasma clearance. The purpose of this study was to evaluate whether the antitumor activity of ORI could be enhanced by loading into solid lipid nanoparticles (SLNs). ORI-loaded SLNs were prepared by hot high pressure homogenization with narrow size distribution and good entrapment efficacy. MTT assay indicated that ORI-loaded SLNs enhanced the inhibition of proliferation against several human cancer cell lines including breast cancer MCF-7 cells, hepatocellular carcinoma HepG 2 cells, and lung carcinoma A549 cells compared with free ORI, while no significant enhancement of toxicity to human mammary epithelial MCF$10 \mathrm{~A}$ cells was shown. Meanwhile, flow cytometric analysis demonstrated that ORI-SLNs induced more significant cell cycle arrest at $S$ and decreased cell cycle arrest at G1/G0 phase in MCF-7 cells than bulk ORI solution. Hoechst 33342 staining and Annexin V/PI assay indicated that apoptotic rates of cells treated with ORI-loaded SLNs were higher compared with free ORI. In summary, our data indicated that SLNs may be a potential carrier for enhancing the antitumor effect of hydrophobic drug ORI.
\end{abstract}

\section{Introduction}

Oridonin (ORI), a tetracycline diterpenoid derived from a traditional Chinese herb Rabdosia rubescens, has been widely used as antibacterial, antinociceptive, and anti-inflammatory agent for years [1-3]. Nowadays, ORI has been clinically used for treating cancer and its antitumor mechanisms of ORI have been well documented [4-7]. ORI exerts its antitumor effect mainly by inhibiting proliferation [8], inducing cell cycle arrest [5], apoptosis, and autophagy [9-11], as well as halting the tumor angiogenesis and metastasis [12]. Caspases, reactive oxygen species (ROS), p53, nuclear factor-kappaB (NF$\kappa \mathrm{B}), \mathrm{MAPK}$, and PI3K/Akt pathways have been demonstrated to be involved in the apoptosis and autophagy-inducing effect of ORI $[10,13,14]$. However, the poor water-solubility and the extremely bitter taste of ORI have become the key limited factors on the further applications of ORI.
In recent years, nanoparticles delivery systems have played an important role in ameliorating the bioavailability of hydrophobic drugs [15]. SLNs is considered to be a suitable nanoparticle delivery system for ORI, for it possesses a mature processing technique as drug delivery system and has stable performance on drug entrapment and drug release [16]. Though solid lipid nanoparticles (SLNs) conjunct with lipid composition, water-soluble component and surfactant could load the poorly water-soluble drug and improve its solubility; the specific studies of the pharmacology function of drugloaded SLNs on cancer cells still need further investigation. Therefore, here exists a critical need to explore and evaluate whether SLNs was a worthy delivery system to treat cancer. In this study, ORI-loaded SLNs were prepared by high pressure homogenization by using glyceryl monostearate, oleic acid, and poloxamer 188. The pharmaceutical actions of cell viability, cellular uptake, cell cycle arrest, and apoptosis treated with 
ORI-loaded SLNs on cancer cells were undertook, aiming to investigate whether ORI-loaded SLNs could heighten the antitumor effect and the related mechanisms.

\section{Materials and Methods}

2.1. Chemicals. Oridonin (98\% purity) was provided by Nanjing Zelang BiomedicTechnology Co., Ltd. (Nanjing, China). Glyceryl monostearate and oleic acid were purchased from Tianjin Bodi Chemical Limited Company (Tianjin, China). Poloxamer 188 was obtained from BASF (German). Dulbecco's Modified Eagle Medium (DMEM) was supplied by Gibco Life Technologies (Grand Island, USA). 3-(4,5Dimethylthiazol-2-yl)-2,5-diphenyltetrazolium bromide (MTT) and coumarin 6 were purchased from SigmaAldrich (St. Louis, MO, USA). 0.25\% (w/v) trypsin/1 mM Ethylene Diamine Tetraacetic Acid (EDTA), phosphatebuffered saline (PBS), Hoechst 33342, propidium iodide (PI), penicillin-streptomycin (PS), and fetal bovine serum (FBS) were obtained from Invitrogen (Carlsbad, CA, USA). Annexin V-FITC/PI apoptosis detection kit was supplied by $\mathrm{BD}$ Biosciences. Solvents including dimethylsulfoxide (DMSO) and methanol were of chromatographic grade and used without further treatment.

2.2. High Performance Liquid Chromatograph (HPLC) Analysis. The determination of ORI content in SLNs was detected by the reversed phase HPLC method. Waters e2695 HPLC system equipped with photodiode array detector (Waters 2998) and Agilent Eclipse XDB-C18 column (4.60 mm $\times$ $250 \mathrm{~mm}, 5 \mu \mathrm{m}$ ) were used to detect the content of each sample. The mobile phase consisting of methanol and water $(52: 48, \mathrm{v} / \mathrm{v})$ was filtered and degassed for $5 \mathrm{~min}$ before analysis. Each sample $(10 \mu \mathrm{L})$ was eluted at $1 \mathrm{~mL} / \mathrm{min}$ flow rate and detected at $235 \mathrm{~nm}$ with a temperature of $30^{\circ} \mathrm{C}$, and the retention time of ORI was at $12 \mathrm{~min}$. A sensitive quantitative assay of ORI was established with a calibration linear curve of $A=31.65 C+10.77$ within the concentration of 3.4$220.0 \mu \mathrm{g} / \mathrm{mL}\left(r^{2}=1\right)$.

2.3. Preparation of SLNs. A hot high pressure homogenization method was chosen to prepare the ORI-loaded SLNs [17]. Briefly, $400 \mathrm{mg}$ glycerol monostearate and $100 \mathrm{mg}$ oleic acid were melted with $18 \mathrm{mg}$ free ORI in water bath at 70$80^{\circ} \mathrm{C}$ to form the oil phase. Meanwhile, $100 \mathrm{mg}$ poloxamer 188 was dissolved in $100 \mathrm{~mL}$ hot Milli-Q water as the aqueous phase. Then the aqueous phase was squirted gently into the oil phase under magnetic stirring at $800 \mathrm{rpm}$. After stirring for $30 \mathrm{~min}$, the preemulsion was further prepared by a high pressure homogenizer (APV 2000, Denmark) at 1000 bar for 10 cycles. The obtained ORI-loaded SLNs was transferred into $50 \mathrm{~mL}$ centrifuge tubes and cooled down immediately to room temperature. Free unentrapped ORI were removed by centrifugation at 3,000 $\mathrm{g}$ for $10 \mathrm{~min}$. Coumarin 6-loaded SLNs were prepared by replacing ORI with coumarin 6. Blank SLNs were obtained in a similar way by eliminating drugs.
2.4. Evaluation of Average Diameter and Zeta Potential. A Zetasizer Nano-ZSP (Malvern, UK) was used to determine the average particle size of ORI-loaded SLNs at a room temperature. All samples were diluted 10 times with water to get a suitable concentration before measurement. All the results were conducted based on at least three independent experiments. Size and shape of SLNs were also observed using transmission electron microscopy (TEM).

2.5. Drug Entrapment Efficiency Determination. Ultracentrifugation was taken to detect the entrapment efficiency (EE) and drug loading content (DLC) of ORI-loaded SLNs. In detail, $2 \mathrm{~mL}$ ORI-loaded SLNs dispersion was precisely put into centrifuge tube and then was centrifuged at $4500 \mathrm{rpm}$ for $30 \mathrm{~min}$ at a room temperature. Then the liquid supernatant was filtered by $0.45 \mu \mathrm{m}$ microporous filtering membrane and transferred into sample vial for HPLC detection (method as the quantification of ORI-loaded SLNs). Besides, $2 \mathrm{~mL}$ ORI-loaded SLNs dispersion was precisely transferred into a centrifuge tube and added with methanol. After ultrasound destruction, the sample was centrifuged at $4500 \mathrm{rpm}$ for $30 \mathrm{~min}$ and then filtered by $0.45 \mu \mathrm{m}$ microporous filtering membrane. These samples were detected by the same HPLC method. Due to ORI-loaded SLNs that could be separated form free ORI by gravity difference, the entrapment efficiency of ORI-loaded SLNs could be indirectly determined by detecting the free drug concentration and initial ORI-loaded SLNs dispersion. To summarize, the EE and DLC of ORIloaded SLNs was calculated by the following equations:

$$
\begin{gathered}
\mathrm{EE}=\frac{W_{I}-W_{F}}{W_{I}} \times 100 \%, \\
\mathrm{DLC}=\frac{W_{I}-W_{F}}{W_{I}-W_{F}+W_{L}} \times 100 \% .
\end{gathered}
$$

Among which, $W_{I}$ represents for the amount of ORI used for assay, $W_{F}$ represents for the amount of free ORI after isolation and $W_{L}$ was the weight of lipid added in system.

2.6. Evaluation of Drug Release In Vitro. Dialysis method was used to investigate the drug release of ORI-loaded SLNs at $37^{\circ} \mathrm{C}$ in vitro. The dialysis bag (Biotopped, USA) and PBS with $0.2 \%(\mathrm{w} / \mathrm{v})$ sodium dodecyl sulfate (SDS) were used as dialysis membrane and dissolution medium separately. Because the dialysis bag could maintain SLNs but allows the diffusion of free ORI release into the dissolution medium, $2 \mathrm{~mL}$ ORI-loaded SLNs dispersion was added into dialysis bag with two ends sealed with dialysis clips. The contrast group was settled with free ORI. Then these bags were soaked in $25 \mathrm{~mL}$ dissolution medium and continuously shaken at $120 \mathrm{rpm}$ at $37^{\circ} \mathrm{C}$. At each testing time point, $0.5 \mathrm{~mL}$ of dissolution medium was aspirated and the same volume fresh dissolution medium was replenished in the container. Lastly, ORI contents in each sample were obtained by using HPLC and the cumulative percentages of free ORI and ORI-loaded SLNs release profiles were figured out. 
2.7. Cell Culture. The human breast cancer cell line MCF7 cells, human hepatocellular carcinoma cell line HepG 2, human lung carcinoma cell line A549, and human mammary epithelial cell line MCF-10A were obtained from American Type Culture Collection. Cells were cultured in DMEM containing $10 \%(\mathrm{v} / \mathrm{v})$ heat-inactivated FBS medium and 1\% antibiotics $\left(100 \mu \mathrm{g} / \mathrm{mL}\right.$ PS) with $5 \% \mathrm{CO}_{2}$ at $37^{\circ} \mathrm{C}$.

2.8. Cell Viability Assay. The inhibition of cellular proliferation could be estimated by MTT assay in previous study [17]. MCF-7 cells, HepG 2 cells, A549 cells, and MCF-10A cells were trypsinized and seeded into 96-well plates at a density of $0.6 \times 10^{4}, 0.8 \times 10^{4}, 0.8 \times 10^{4}$, and $0.8 \times 10^{4}$ cells per well, respectively. The cells were treated with different concentrations of free ORI, ORI-loaded SLNs, blank-loaded SLNs, and free ORI+ blank loaded SLNs for $24 \mathrm{~h}$ and $48 \mathrm{~h}$, respectively. Then cell viabilities were detected by adding medium containing MTT $(1 \mathrm{mg} / \mathrm{mL})$ and incubated for $4 \mathrm{~h}$ at $37^{\circ} \mathrm{C}$. After removing the MTT solution, the generated formazan crystals were dissolved by DMSO and the absorbance of each group was recorded by a SpectraMax M5 microplate reader (Molecular Devices, USA) at $570 \mathrm{~nm}$. On the other hand, the group of the same dosage of free ORI spiked with blank-loaded SLNs was set up as a controlled trail to see whether there is a difference between ORI entrapped with SLNs and the physical mixture of free ORI and SLNs. Contrasting with respective controls, the optical density (OD) of processed cells indicates the percentage of cell survival in related wells (cell viability $=\mathrm{OD}_{\text {average }}$ value of treatment group/OD $\mathrm{D}_{\text {average }}$ of the control group).

2.9. Cellular Uptake Study. To analyze the internalization of SLNs into MCF-7 cells, coumarin 6 was incorporated into SLNs, and its concentration was detected by flow cytometry. MCF-7 $\left(1.2 \times 10^{5}\right)$ had been cultured into 12-well plates and incubated for $24 \mathrm{~h}$. Then, coumarin 6-loaded SLNs and free coumarin 6 solution with $100 \mathrm{ng} / \mathrm{mL}$ concentration was added into each corresponding well for $1,2,4$, and $12 \mathrm{~h}$ incubation. After fixed time intervals, related cells were collected and washed twice with PBS to remove the nomadic coumarin 6. Finally, the fluorescence of collected cells was detected by flow cytometry on FITC channel. For observation by fluorescence microscopy, the SLNs uptake profiles were detected by In Cell 2000 Analyzer. Breast cancer cells MCF$7\left(1.5 \times 10^{5}\right)$ were seeded in 96-well plate and incubated until they were added with the coumarin 6-loaded SLNs and corresponding coumarin 6 solutions for 1, 2, 4, and $12 \mathrm{~h}$ incubation. After being washed twice by PBS, cells were then fixed with PFA for $10 \mathrm{~min}$ and then immersed in PBS. The images of cells could reveal the uptake of SLNs by detecting its corresponding fluorescence.

2.10. Cell Cycle Analysis. MCF-7 $\left(1.2 \times 10^{5}\right)$ were trypsinized and seeded in 6-well plates and then incubated for $24 \mathrm{~h}$. After $24 \mathrm{~h}$ starvation by using serum-free DMEM medium, cells were treated with different concentrations of free ORI, ORI-loaded SLNs for another $24 \mathrm{~h}$. Meanwhile, blank-loaded SLNs group was settled for comparison. Subsequently, cells were collected by centrifugation at $500 \mathrm{~g}$ for $5 \mathrm{~min}$ after being washed by PBS twice. Then cells were fixed in 70\% ice-cold ethanol at $-20^{\circ} \mathrm{C}$ overnight. Then the cells were collected by centrifugation and stained by $50 \mu \mathrm{L}$ PI stain solution containing $20 \mu \mathrm{g} / \mathrm{mL}$ PI and $8 \mu \mathrm{g} / \mathrm{mL}$ RNase for each well for 15 min while avoiding light. By analyzing with a FACS flow cytometer CantoTM (BD Biosciences, San Jose, USA), the data of the distributions of G0/G1, G2/M, and S phases of MCF-7 cells were detected and analyzed by software ModFit LT (version 3.0).

2.11. Analysis of Nuclear Morphology. After culturing for $24 \mathrm{~h}$ with different concentrations of ORI-loaded SLNs formulation and free ORI of the same dosage with previous experiments, MCF-7 cells $\left(1.0 \times 10^{4}\right)$ seeded in 96 -well plate were fixed with paraformaldehyde (PFA) at $4^{\circ} \mathrm{C}$ and then stained by Hoechst 33342 staining solution $(2 \mu \mathrm{g} / \mathrm{mL})$ and incubated for $5 \mathrm{~min}$ at room temperature. Then staining solutions were removed and the cells were washed with PBS twice. Cells were soaked in PBS and observed by In Cell Analyzer 2000 (GE Healthcare, USA). Apoptotic cells were recognized by condensed, fragmented, or degraded nuclei, and the results were based on at least three independent experiments.

2.12. Apoptotic Cell Determination. MCF-7 cells $\left(1.2 \times 10^{6}\right)$ seeded in 6-well plate were treated with different concentrations of free ORI, ORI-loaded SLNs solution for $24 \mathrm{~h}$, respectively. Then the cells were collected after treated with trypsin and centrifugation. Cells were washed twice with PBS and then $100 \mu \mathrm{L}$ binding buffer for each group was added for resuspending cells. Collected cells were added with $5 \mu \mathrm{L}$ Annexin V for $15 \mathrm{~min}$ and then added $5 \mu \mathrm{L}$ PI for $10 \mathrm{~min}$ without light. Cell apoptosis phenomenon was analyzed by flow cytometer $(\mathrm{BD})$. A total of $1.0 \times 10^{5}$ cells were analyzed in each individual sample.

2.13. Data Analysis. All the results were conducted as the means \pm SD and all the experiments were taken for at least three experiments. Statistical comparisons were presented by the analysis of variance with student's $t$-test. The values of $P \leq 0.05$ and $P \leq 0.01$ were considered as statistically significant.

\section{Results and Discussion}

3.1. Characterization of ORI-Loaded SLNs. Oridonin-loaded SLNs were prepared by high pressure homogenization using glyceryl monostearate, oleic acid, and poloxamer 188. The mean particle size of the ORI-SLNs was $108.53 \pm 10.92 \mathrm{~nm}$, with a good PDI value (Table 1) (Figure 1(a)). Besides, the mean zeta potential was $-37.97 \pm 3.78 \mathrm{mV}$, indicating that the SLN system was physically stable. Compared with blankloaded SLNs, the particle size of ORI-loaded SLNs was a little bit small and the zeta potential was extremely close, indicating that the incorporation of ORI did not significantly increase the volume of solid phase. Viewed from the data of 
TABLE 1: Characteristics of ORI-loaded SLNs and blank-loaded SLNs.

\begin{tabular}{|c|c|c|c|c|c|}
\hline Nanoparticles & $\begin{array}{c}\text { Particle size } \\
(\mathrm{nm} \pm \mathrm{SD})\end{array}$ & $\begin{array}{c}\text { PDI } \\
( \pm \mathrm{SD})\end{array}$ & $\begin{array}{l}\text { Zeta potential } \\
(\mathrm{mV} \pm \mathrm{SD})\end{array}$ & $\begin{array}{l}\text { Drug entrapped } \\
\quad(\% \pm \mathrm{SD})\end{array}$ & Drug loading efficiency \\
\hline ORI-loaded SLNs & $108.53 \pm 10.92$ & $0.21 \pm 0.01$ & $-37.97 \pm 3.78$ & $67.49 \pm 1.99$ & $3.12 \pm 0.02$ \\
\hline ORI-loaded SLNs (14 days after) & $114.10 \pm 4.62$ & $0.27 \pm 0.03$ & $-33.90 \pm 0.26$ & $65.49 \pm 2.2$ & $3.01 \pm 0.02$ \\
\hline Blank-loaded SLNs & $114.03 \pm 2.25$ & $0.17 \pm 0.01$ & $-36.07 \pm 1.39$ & - & - \\
\hline
\end{tabular}

PDI: polydispersity index; SD: standard deviation.

Table 1, it was shown that both ORI-loaded SLNs and blankloaded SLNs possess good conditions on particle size and zeta potential. Besides, most of the particles were observed to be distributed between 100 and $200 \mathrm{~nm}$ under the TEM (Figure 1(b)), which were correlated well with the results of the particle size analysis using dynamic light scattering. Furthermore, the big and small ones in ORI-loaded SLNs were seen, and this may be seen as ORI entrapped SLNs and empty SLNs.

Drug's curative effects could be notably influenced by its different kinds of existence forms during the absorption, distribution, metabolism, and excretion phase. ORI encapsulated in lipid nucleus, ORI absorbed on the surface of SLNs and free OIR in the dispersion are the main forms that exist in SLNs dispersion. Using ultracentrifugation method, our study concluded that the average EE and DLC of ORI-loaded SLNs were $67.49 \%$ and $3.12 \%$, respectively (Table 1 ). The EE of ORI-loaded SLNs was not very high; this may due to the long centrifugation time and the drug leak-out caused by the high eccentricity. Meanwhile, high recurrence and accuracy had demonstrated that the ultracentrifugation was sensitive, accurate, and convenient measurement for detecting the EE of ORI-loaded SLNs. After 14 days' preservation, ORI-loaded SLNs not only present stable size and zeta potential but also possess good drug entrapment and drug loading profiles (Table 1). Briefly, as shown in Table 1 , it was verified that the obtained ORI-SLNs possessed a stable and valuable quality to load ORI and keep good quality in the meantime.

3.2. Drug Release Study of ORI-Loaded SLNs. In Figure 1(c), it is easy to see that ORI-loaded SLNs release rate was slower than free ORI in PBS containing 0.2\% (w/v) SDS at $37^{\circ} \mathrm{C}$ during the testing time. It is speculated that the main reason was due to SLNs encapsulated ORI in the lipid core, which could stand in the way of ORI release. Contributed to the extended time of release, ORI-loaded SLNs resulted in sustained release ability, which is a benefit to prolong the retention time of ORI and efficacy quality.

3.3. ORI-Loaded SLNs Enhanced the Inhibition Effect of Cancer Cell Proliferation. The succinate dehydrogenase in metabolically active cells could transform MTT to formazan crystals, which could be detected as a credible evaluation index of cell viability. The proliferation of several human cancer cell lines was determined by MTT assay and the results showed that with the treatment of ORI-loaded SLNs the growth of tumor cell could be substantially delayed. Our studies indicated that the cell proliferation was inhibited in the order of ORI-loaded
SLNs $>$ free ORI $>$ blank SLNs (Figure 2). With approximate $\mathrm{IC}_{50}$ of $40.1 \mu \mathrm{M}$ of free ORI and $22.6 \mu \mathrm{M}$ of ORI-loaded SLNs after $24 \mathrm{~h}$ treatment, $15.2 \mu \mathrm{M}$ of free ORI and $18.7 \mu \mathrm{M}$ of ORIloaded SLNs after $48 \mathrm{~h}$ treatment, respectively, cell viabilities of MCF-7 on both free ORI and ORI-loaded SLN resulted in a concentration-dependent manner. Data further showed that ORI-loaded SLNs significantly inhibited the cell proliferation in $24 \mathrm{~h}$ incubation compared with $48 \mathrm{~h}$ incubation, and one of these reasons may be due to the fact that sustained release had almost reached saturation at $24 \mathrm{~h}$, which may affect the uptake of ORI. In summary, we convinced that ORI-loaded SLNs had a more significant effect of inhibiting proliferation on MCF-7 cells than free ORI at each tested dosage. Besides, the toxicity of human hepatocellular carcinoma cell line HepG 2, human carcinoma cell line A549, and human normal breast cell line MCF-10A treating with the same dosage of free ORI and ORI-loaded SLNs were shown in Figure 2; the $\mathrm{IC}_{50}$ of ORIloaded SLNs were $30.1 \mu \mathrm{M}$ (HepG 2) and $25.3 \mu \mathrm{M}$ (A549), and the $\mathrm{IC}_{50}$ of free ORI were $39.2 \mu \mathrm{M}$ (HepG 2) and $29.6 \mu \mathrm{M}$ (A549) after $24 \mathrm{~h}$ treating time. For $48 \mathrm{~h}$ treatment, the $\mathrm{IC}_{50}$ of HepG 2 and A549 treated with free ORI and ORI-loaded SLNs were $11.8 \mu \mathrm{M}$ and $10.0 \mu \mathrm{M}$ (HepG 2) and $40.3 \mu \mathrm{M}$ and $35.8 \mu \mathrm{M}$ (A549), respectively. The MTT data demonstrated that ORI-loaded SLNs could enhance the inhibition of A549 cells proliferation during the detected concentrations to some extent after $48 \mathrm{~h}$ incubation, thought no obvious enhancement was mentioned on $24 \mathrm{~h}$ treatment samples. On the other hand, HepG 2 cells showed a slight proliferation inhibition on $24 \mathrm{~h}$ treatment, while there was no significant difference in the toxicity of HepG 2 after $48 \mathrm{~h}$ treatment. According to the results of cell viability, we found that the inhibition degrees of cells' proliferation treating with ORI-loaded SLNs were different on these cancer cells that were obtained from different parts of the body. These results may be due to MCF7, HepG 2, A549 having different uptake amounts and rates of ORI-loaded SLNs and free ORI. However, the IC50 of free ORI spiked with blank SLNs on MCF-7, HepG 2, and A549 were $39.8 \mu \mathrm{M}, 45.8 \mu \mathrm{M}$, and $36.7 \mu \mathrm{M}$ with for $24 \mathrm{~h}$ treatment and $32.8 \mu \mathrm{M}, 18.8 \mu \mathrm{M}$, and $40.7 \mu \mathrm{M}$ RI-loaded SLNs for $48 \mathrm{~h}$ treatment. It was evidenced that ORI loaded SLNs had higher inhibition on the proliferation of these cancer cells compared with free ORI spiked with blank SLNs group. It was further presented that the inhibiting effect of ORI could be enhanced by encapsulating ORI in SLNs. On the other hand, compared with free ORI spiked with blank-loaded SLNs group, ORIloaded SLNs treated group had a better inhibition of cell proliferation on MCF-7, HepG 2, and A549 cancer cells, which may be benefited from the stable existence form of ORI in the core of ORI-loaded SLNs. Weather ORI entrapped in 


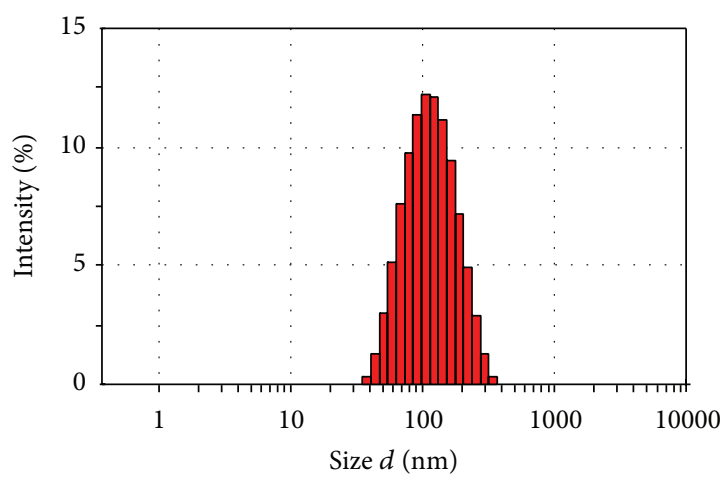

(a)

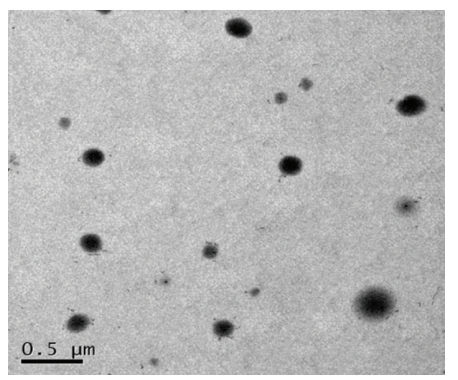

Instant sample

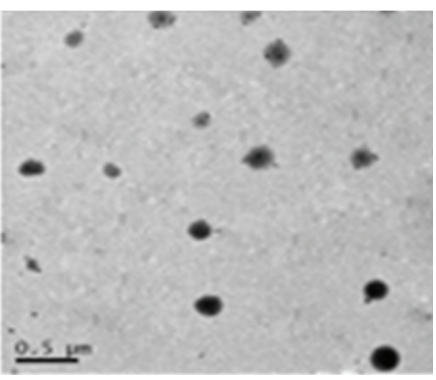

Sample reserved for 14 days

(b)

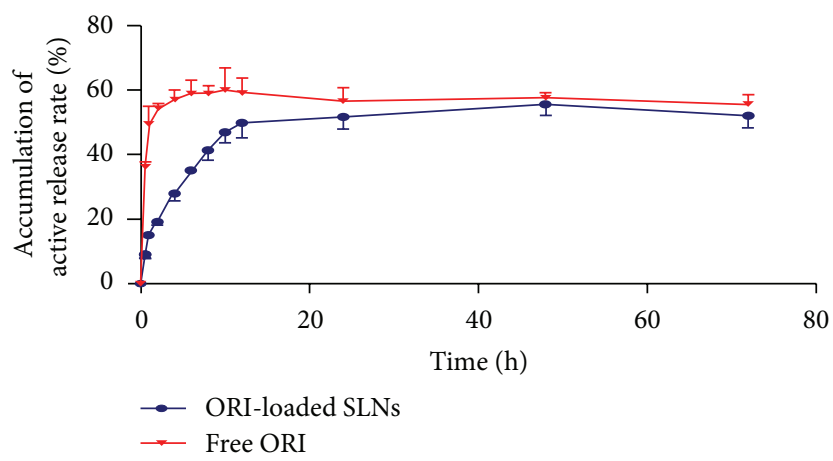

(c)

FIgURE 1: Particle size distribution of ORI-loaded SLNs determined by dynamic light scattering (DLS) (a) and transmission electron microscopy (TEM) (b). Drug release profiles of free ORI and ORI-loaded SLNs in vitro (c).

SLNs is a key evidence to demonstrate that ORI-loaded SLNs possess a sustained drug release profile and could cause more significant cell death, which is different from physical mixture of ORI and SLNs. Besides, there was almost no toxicity on MCF-10A cells by treating with free ORI and ORI-loaded SLNs. As it had obvious toxicity results of ORI-loaded SLNs, in the next step, breast cancer cells MCF-7 was chosen to be tested in further studies.

3.4. Cellular Uptake Study. The uptake of SLNs by cancer cells is an important factor to assess its nanotoxicity. In order to investigate the cellular uptake of SLNs, the fluorescently labeled SLNs is commonly used, and the intracellular properties of cells could be quantitated by fluorescent maker coumarin 6 . The presented study demonstrated that the uptake of fluorescent SLNs slightly decreased during the early $4 \mathrm{~h}$, while it was significantly increased at $12 \mathrm{~h}$ time compared with the marker solution (Figures 3(a) and 3(b)). In the column diagram (Figure 3(c)), it may be a cell ejection during the incubation time for the uptake degree of coumarin 6 solution were gradually decrease as time went on, and the similar tendency was shown on the SLNs group for the early $4 \mathrm{~h}$. Nevertheless, the reverse rising fluorescence of SLNs on $12 \mathrm{~h}$ might give referable evidence that SLNs could contribute to the uptake of drug and had sustained release ability. Meanwhile, images clearly evidenced that the SLNs taken up by breast cancer cells MCF-7 could prolong the uptake time and deepen the uptake degree compared with free maker.

3.5. ORI-Loaded SLNs Induced Cell Cycle Arrest. The cycle progression was examined by a flow cytometry to confirm whether the inhibition of proliferation on MCF-7 cells was related to the cell cycle arrest [18]. Our previous research had demonstrated that ORI could induce cell cycle arrest of MCF-7 cells at G2/M phase [7]. In this experiment, after $24 \mathrm{~h}$ exposure to $20 \mu \mathrm{M}$ and $10 \mu \mathrm{M}$ free ORI and ORI-loaded SLNs, MCF-7 cells were arrested at the G2/M phase and presented significant increase at S phase (Figure 4(d)). The number of MCF-7 cells treated with $10 \mu \mathrm{M}$ and $20 \mu \mathrm{M}$ free ORI at the G2/M phase increased from $20.64 \%$ to $28.90 \%$. Furthermore, after being treated with the same $20 \mu \mathrm{M}$ ORI, cells exposed to ORI-loaded SLNs increased to $30.50 \%$, compared $20 \mu \mathrm{M}$ free ORI with $28.90 \%$ (Figure 4(b)). Specifically, during the following $24 \mathrm{~h}$ exposure to $10 \mu \mathrm{M}$ and $20 \mu \mathrm{M}$ ORI-loaded SLNs, the S phase cells of MCF-7 increased from $33.47 \%$ to $48.46 \%$ (Figure 4(d)). The number of MCF-7 cells treated with $20 \mu \mathrm{M}$ ORI-loaded SLNs at G1/G0 phase was significantly decreased to $22.54 \%$, compared to the cells treated with $20 \mu \mathrm{M}$ free ORI which were $37.63 \%$ (Figure $4(\mathrm{c})$ ). In summary, it was demonstrated that ORI-loaded SLNs had a more significant function of arresting cell cycle at G2/M phase than free ORI at each tested dosages. 

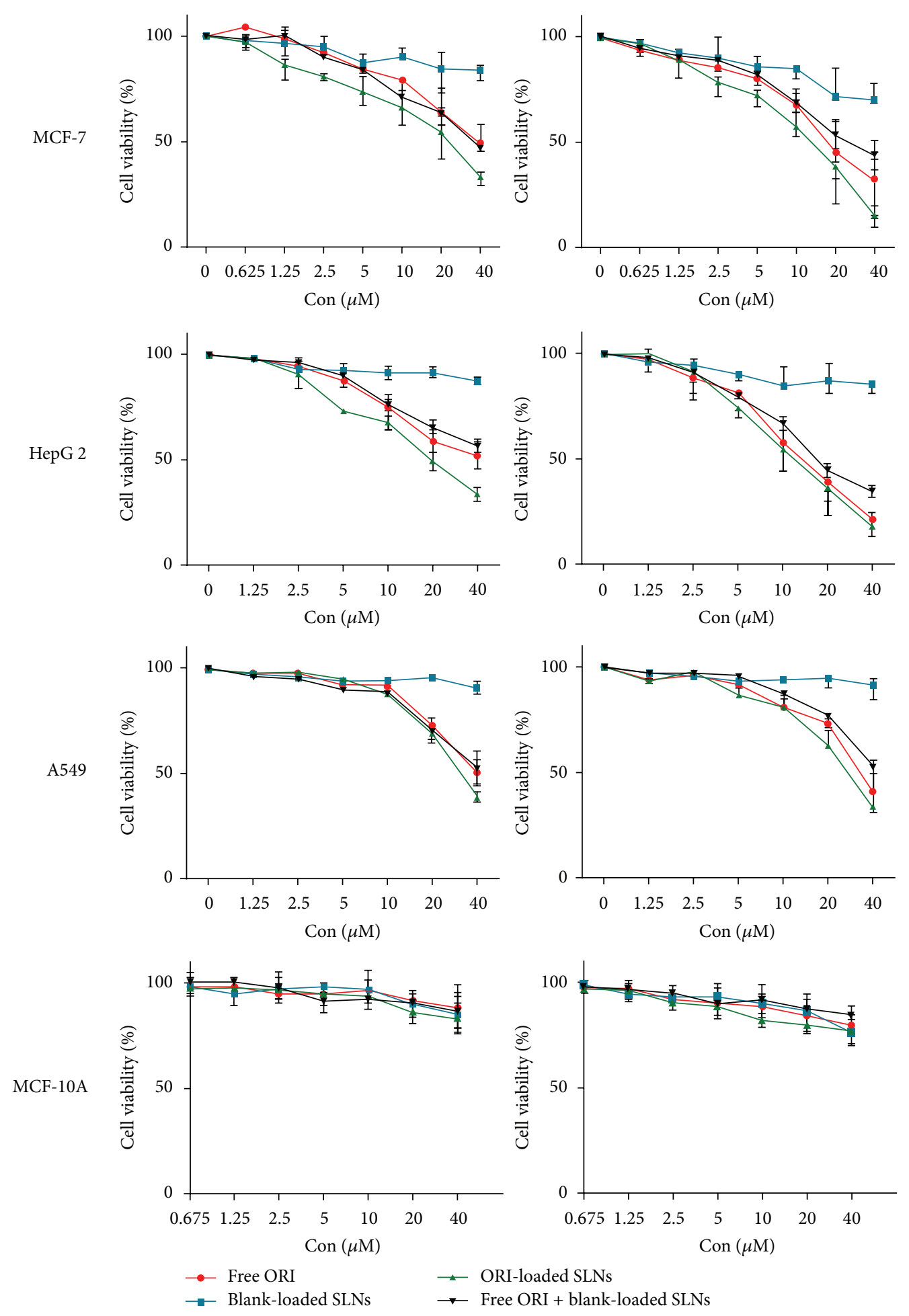

FIGURE 2: Cell viability results of breast cancer cells MCF-7, hepatocellular carcinoma cells HepG 2, lung carcinoma cells A549, and normal breast cells MCF-10A treated with different dosages of free ORI, ORI-loaded SLNs, and blank-loaded SLNs for $24 \mathrm{~h}$ and $48 \mathrm{~h}$ incubation. Error bars represent the SD value of three experiments.

3.6. ORI-Loaded SLNs Treatment Induced Apoptosis. Apoptosis in breast cancer cell could be induced by treating with ORI [9]. To perform a comprehensive view on the apoptotic phenomenon on breast cancer cell MCF-7, Hoechst 33342 staining pictures (Figures 5(a) and 5(b)) were presented to give more detailed illustrations. As expected, pictures demonstrated that the greatest degree of apoptosis was induced by ORI-loaded SLNs at each dosage. The amount of cells of 


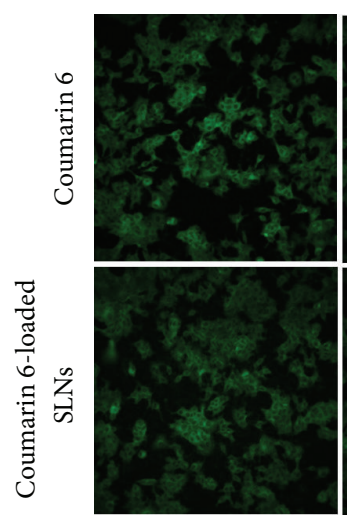

$1 \mathrm{~h}$

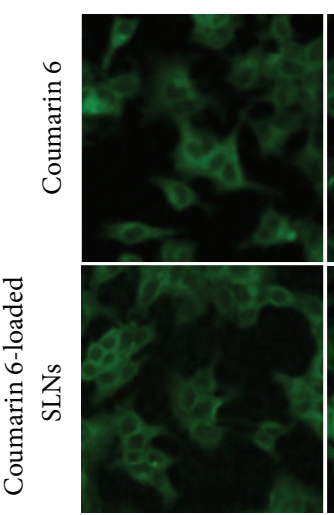

$1 \mathrm{~h}$
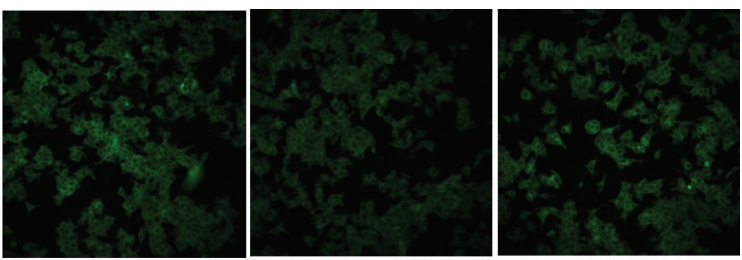

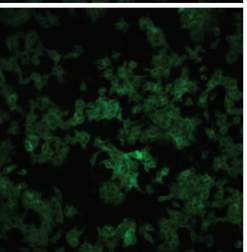

$2 \mathrm{~h}$

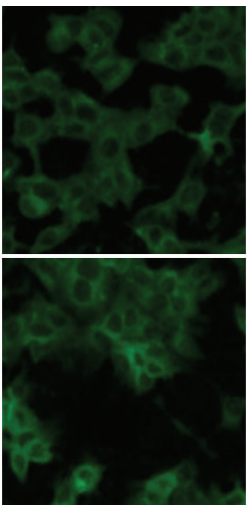

$2 \mathrm{~h}$

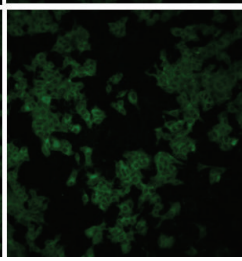

$4 \mathrm{~h}$

(a)

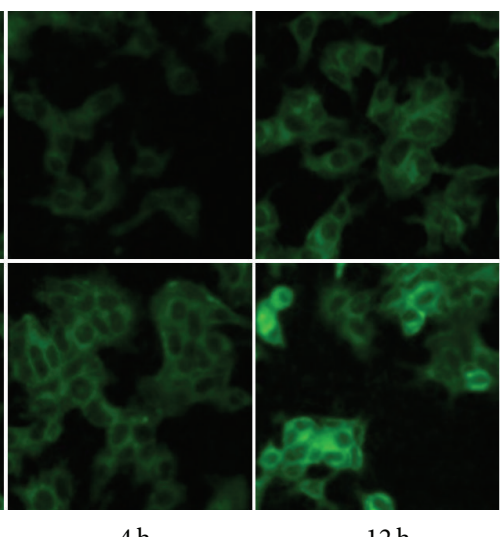

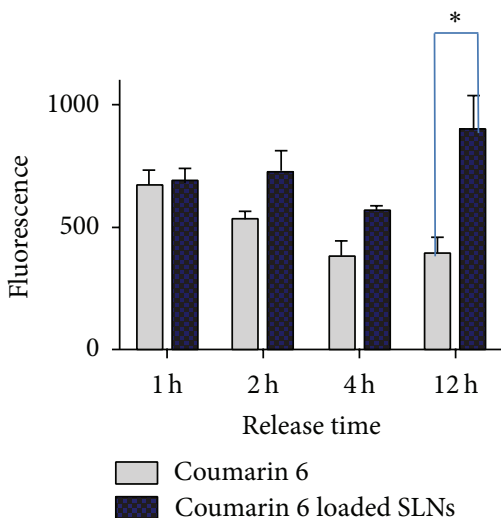

(c)

(b)

Figure 3: Cellular uptake fluorescent data of free coumarin 6 and coumarin 6-loaded SLNs by breast cancer cells MCF-7 at $100 \mathrm{ng} / \mathrm{mL}$ concentration in different horizons (a), (b). Cellular uptake fluorescent images of breast cancer cells MCF-7 treated with SLNs and maker solutions (c). Error bars represent the SD value of three experiments; ${ }^{*} P<0.05$, ORI-loaded SLNs versus free ORI.

$20 \mu \mathrm{M}$ ORI-loaded SLNs group was obviously decreased and the reason may be considered as the cells were in a severe apoptosis state after treating with $20 \mu \mathrm{M}$ and then washed by PBS. On the other hand, ORI-loaded SLNs of $20 \mu \mathrm{M}$ and $10 \mu \mathrm{M}$ showed a stronger effect of apoptosis on MCF-7 cells compared with free ORI at the same dosages. Meanwhile, cells in control and blank SLNs groups displayed a weak fluorescence and had slight morphologic changes. In summary, obvious fluorescence in ORI-loaded SLNs indicated that the apoptotic effects were enhanced by SLNs preparations.

Following free ORI and ORI-loaded SLNs treatments, cells were detected by using an Annexin V/PI apoptosis kit. Early apoptotic cells could be characterized by the exposed phosphatidylserine bounding to Annexin V-FITC but not to PI and late apoptotic stages could be labeled both with Annexin V-FITC and PI. We observed different levels of apoptosis on MCF-7 cells in both $10 \mu \mathrm{M}$ and $20 \mu \mathrm{M}$ treated with free ORI and ORI-loaded SLNs for $24 \mathrm{~h}$ (Figure 6(a)). Specifically, the percentages of apoptosis on early and late apoptotic stages of ORI-loaded SLNs (50.3\% and $26.7 \%$ for $20 \mu \mathrm{M}$ and $10 \mu \mathrm{M}$ ) were higher than free ORI treated MCF-7 cells $(37.1 \%$ and $24.0 \%$ for $20 \mu \mathrm{M}$ and $10 \mu \mathrm{M}$ ) (Figure $6(\mathrm{~b})$ ). These findings demonstrated that ORI-loaded SLNs could markedly induce early and late apoptosis on MCF-7 cells. Combined with the cellular uptake results, it was deduced that the enhanced apoptosis on ORI-loaded SLNs treated MCF-7 cells was caused by the increased uptake of ORI through the SLNs vehicle. In addition, compared with free ORI treated cells at each concentration, ORI-loaded SLNs had a more intense apoptotic effect at early apoptosis stage.

\section{Conclusion}

The present study demonstrated that ORI-loaded SLNs, which is prepared by high pressure homogenization with narrow size distribution and sustained release, could enhance the antiproliferation effect of ORI against several human cancer cell lines including breast cancer MCF-7 cells, hepatocellular carcinoma HepG 2 cells, lung carcinoma A549 cells compared with free ORI, while it was shown no significant enhancement of toxicity of human mammary epithelial MCF-10A cells. Cellular uptake studies clearly evidenced that the SLNs treated on breast cancer cells MCF-7 could prolong the uptake time and deepen the uptake degree. Further flow cytometric analysis illustrated that ORI-loaded SLNs decreased cell cycle arrest at G1/G0 and presented significant 

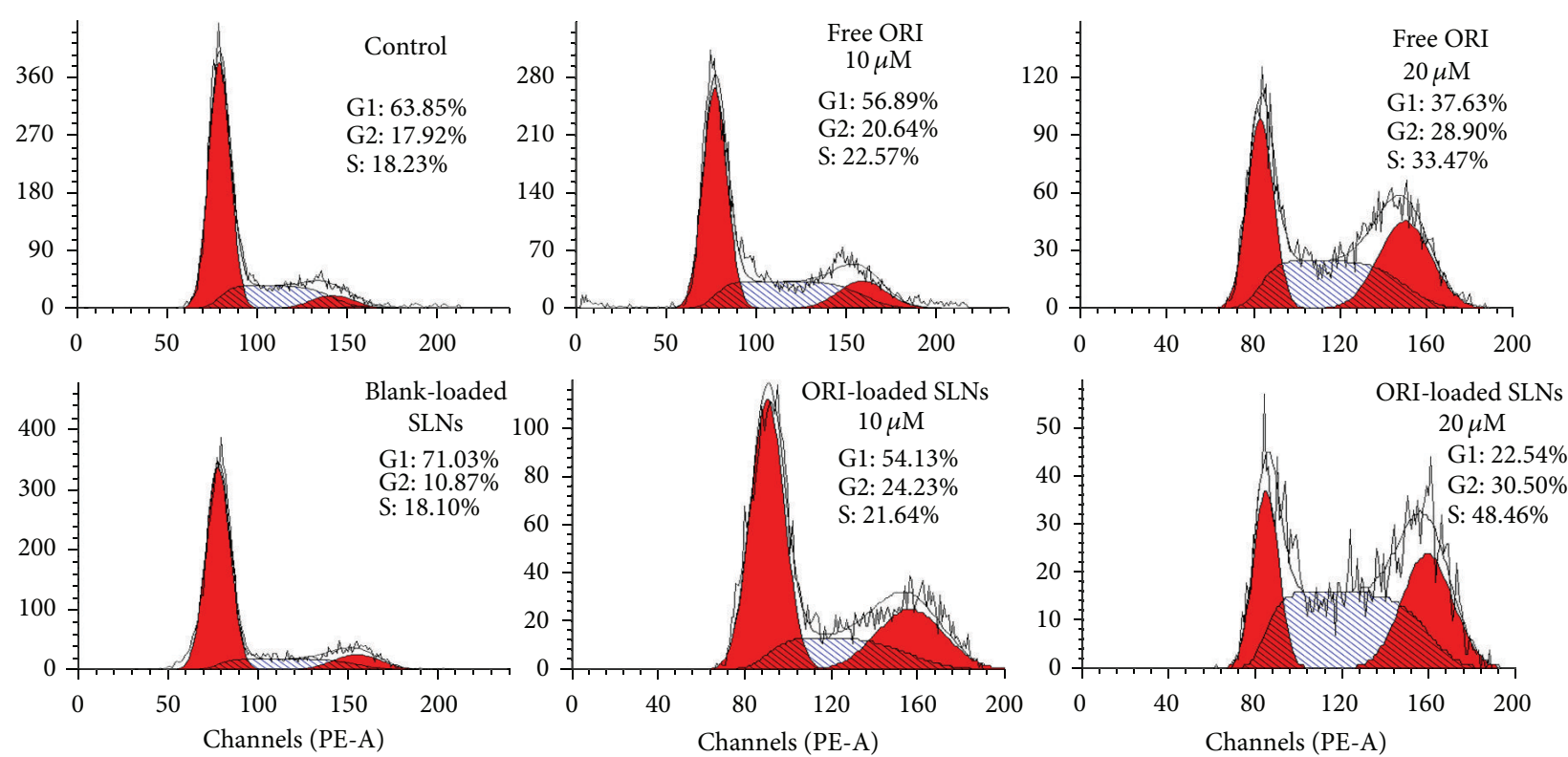

$\begin{array}{ll}\text { Debris } & \square \text { Dip G1 } \square \text { Dip S } \\ \text { Aggregates } & \square \text { Dip G2 }\end{array}$

(a)

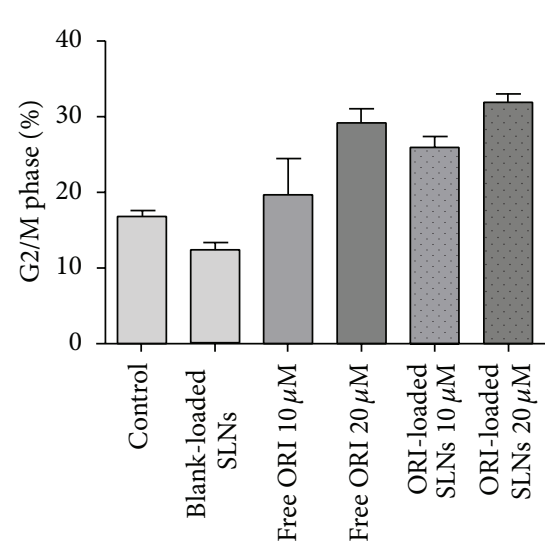

(b)

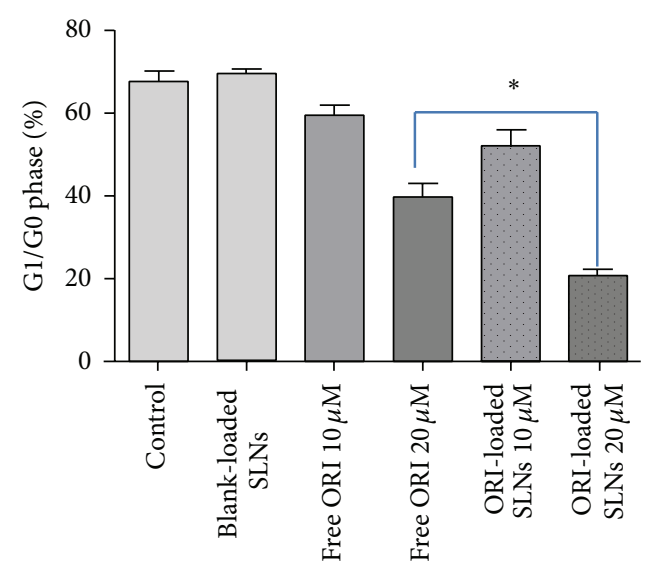

(c)

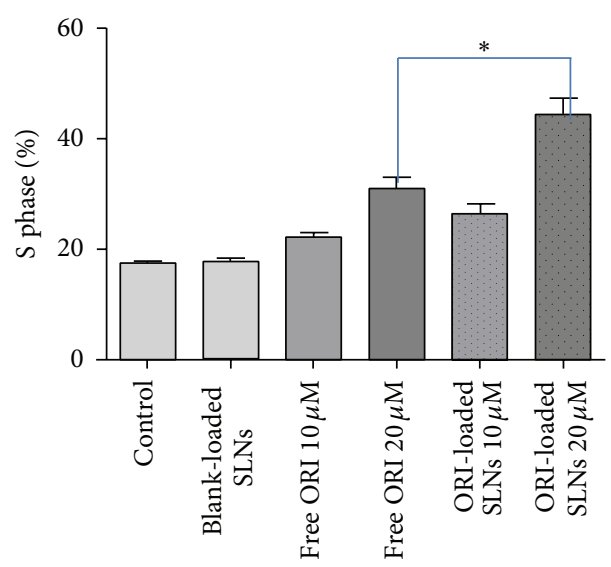

(d)

FIGURE 4: Cell cycle distributions of MCF-7 cells were performed by flow cytometric detection. The distributions of different solutions treated with free ORI and ORI-loaded SLNs at the concentrations of $20 \mu \mathrm{M}$ and $10 \mu \mathrm{M}$ for $24 \mathrm{~h}$ were presented and compared with control and blank SLNs (a). The percentages of G2/M cells treated with free ORI and ORI-loaded SLNs at the concentrations of $20 \mu \mathrm{M}$ and $10 \mu \mathrm{M}$ (b) and the percentages of cells on G1/G0 (c) and S (d) were also presented. ${ }^{*} P<0.05$ versus control. 

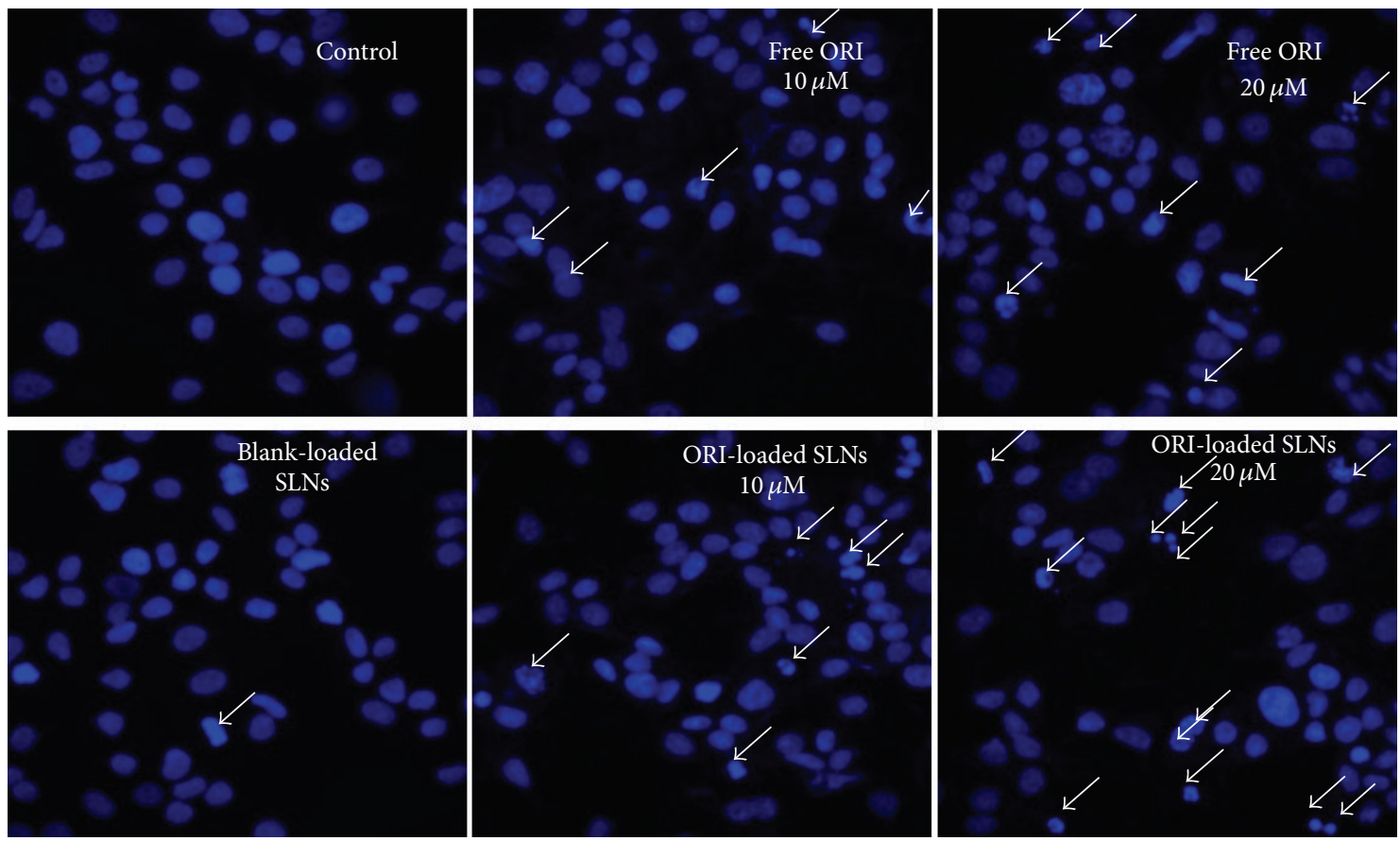

(a)
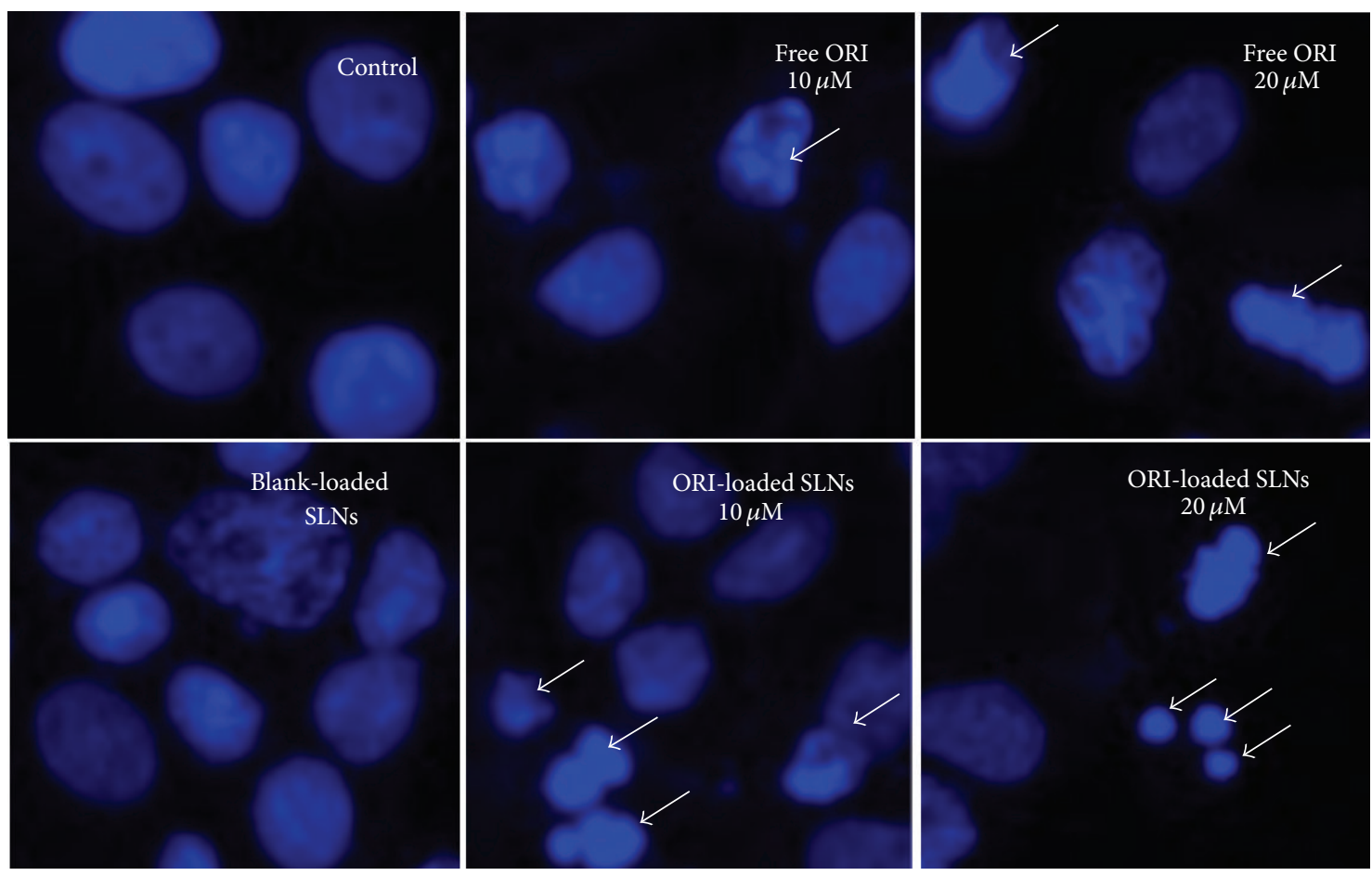

(b)

FIgURE 5: Apoptotic morphology of MCF-7 cells treated with $20 \mu \mathrm{M}$ and $10 \mu \mathrm{M}$ free ORI and ORI-loaded SLNs for $24 \mathrm{~h}$ in different horizons (a), (b).

increase at S phase than free ORI. Furthermore, observable apoptosis results demonstrated that ORI-SLNs could induce higher apoptotic rates compared with free ORI on MCF-7 cells. Taken together, SLNs could be considered an effective carrier for ORI to treat breast cancer via enhancing apoptotic inducing effect. Nevertheless, all experiments in this study were carried out just in in vitro models; in vivo antitumor studies still deserve further research.

\section{Conflict of Interests}

The authors declare no conflict of interests in this work. 

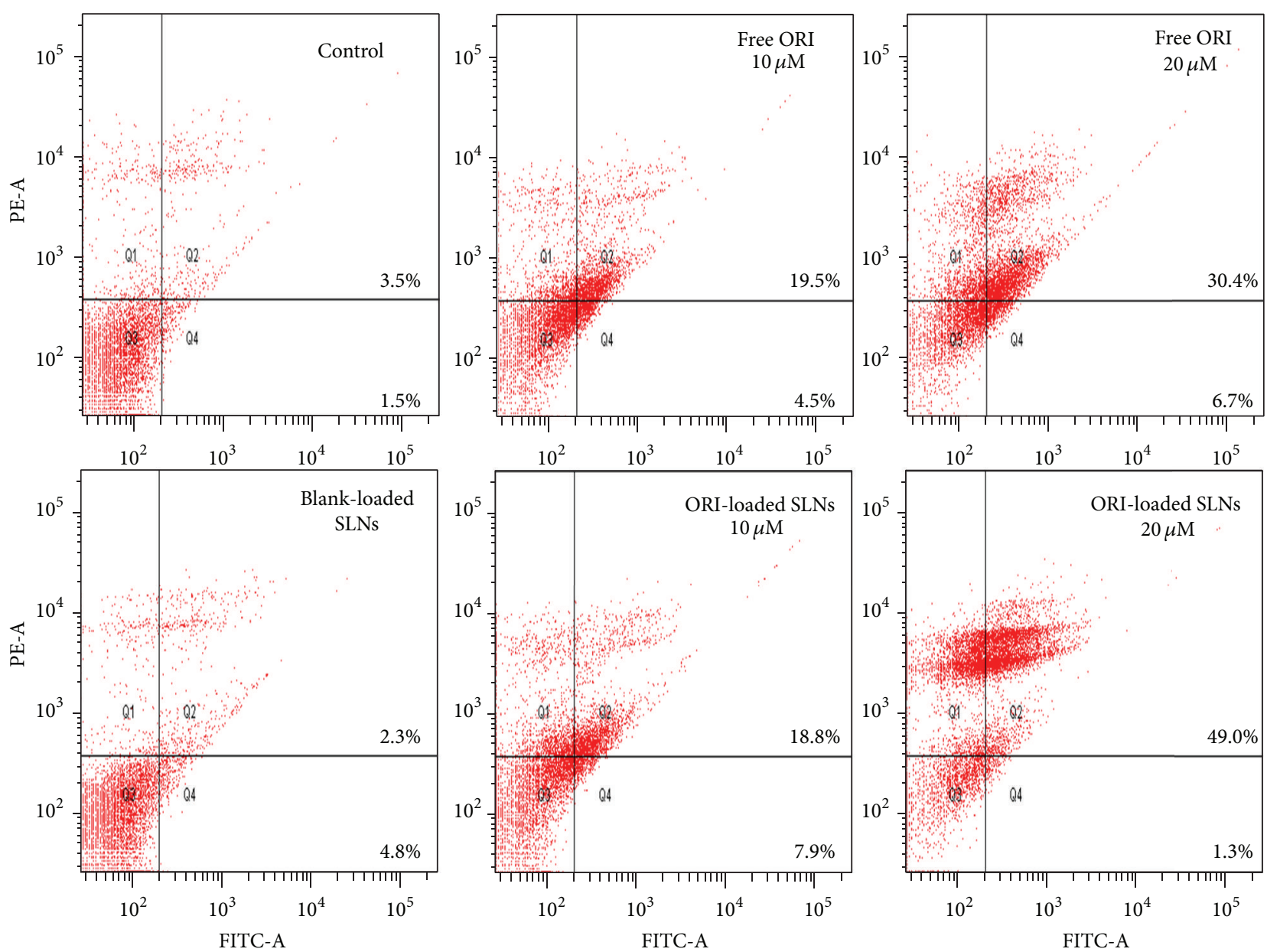

(a)

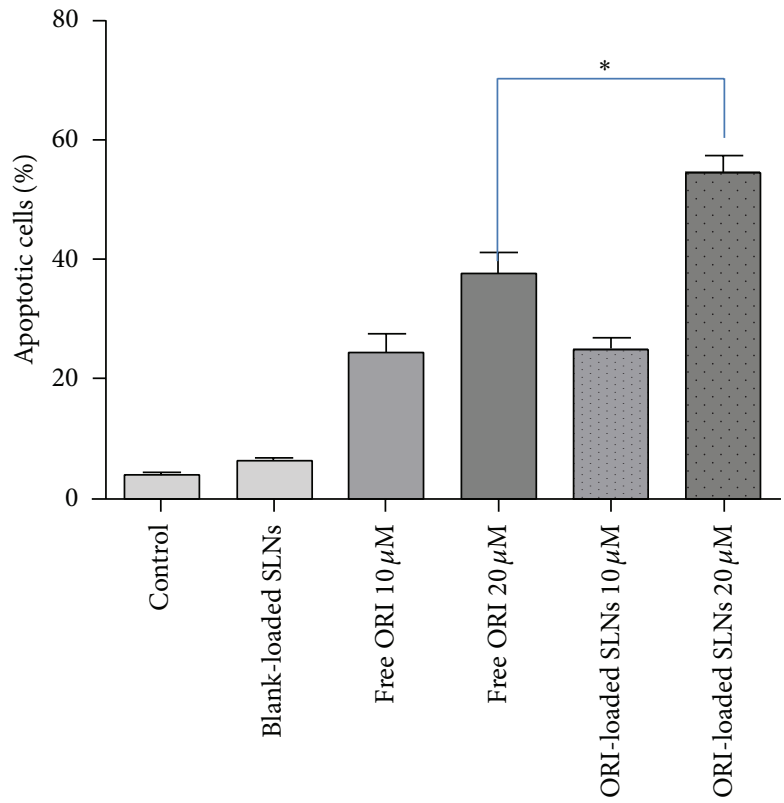

(b)

FIgURE 6: Cell apoptosis of MCF-7 cells after treatment of different solutions (free ORI and ORI-loaded SLNs) at different concentrations $(20 \mu \mathrm{M}$ and $10 \mu \mathrm{M})$ for $24 \mathrm{~h}$. Q1, Q2, Q3, and Q4 phases correspondingly stand for necrotic cells, late apoptotic cells, live cells, and early apoptotic cells (a). Values of apoptotic cells (Q2 and Q4) are presented by bar graph (b). ${ }^{*} P<0.05$ versus control; ${ }^{* *} P<0.01$ versus control. 


\section{Authors' Contribution}

Lu Wang and Shengpeng Wang contributed equally to this work.

\section{Acknowledgments}

This study was supported by the Macao Science and Technology Development Fund (077/2011/A3), the Research Fund of the University of Macau (SRG025-ICMS13-CMW), Beijing Joint Project Specific Funds, and Fund of State Administration of TCM (200907001-5).

\section{References}

[1] A.-P. Hu, J.-M. Du, J.-Y. Li, and J.-W. Liu, “Oridonin promotes $\mathrm{CD} 4^{+} / \mathrm{CD} 25^{+}$Treg differentiation, modulates Th1/Th2 balance and induces HO-1 in rat splenic lymphocytes," Inflammation Research, vol. 57, no. 4, pp. 163-170, 2008.

[2] Y. Xu, Y. Xue, Y. Wang, D. Feng, S. Lin, and L. Xu, "Multiplemodulation effects of oridonin on the production of proinflammatory cytokines and neurotrophic factors in LPS-activated microglia," International Immunopharmacology, vol. 9, no. 3, pp. 360-365, 2009.

[3] L. Zhou, L. Sun, H. Wu et al., "Oridonin ameliorates lupus-like symptoms of Mrl mice by inhibition of B-cell activating factor (Baff)," European Journal of Pharmacology, vol. 715, no. 1-3, pp. 230-237, 2013.

[4] X.-T. Li, C. Lin, and P.-Y. Li, "Characteristics of the cytostatic effects of oridonin in vitro," Zhongguo Yao Li Xue Bao, vol. 7, no. 4, pp. 361-363, 1986.

[5] H. Wang, Y. Ye, J.-H. Chu et al., "Oridonin induces G2/M cell cycle arrest and apoptosis through MAPK and p53 signaling pathways in HepG2 cells," Oncology Reports, vol. 24, no. 3, pp. 647-651, 2010.

[6] Y. Guo, Q. Shan, Y. Gong et al., "Oridonin in combination with lmatinib exerts synergetic anti-leukemia effect in $\mathrm{Ph}+$ acute lymphoblastic leukemia cells in vitro by inhibiting activation of Lyn/Mtor signaling pathway," Cancer Biology \& Therapy, vol. 13, no. 13, pp. 1244-1254, 2012.

[7] S. Wang, Z. Zhong, J. Wan et al., "Oridonin induces apoptosis, inhibits migration and invasion on highly-metastatic human breast cancer cells," The American Journal of Chinese Medicine, vol. 41, no. 1, pp. 177-196, 2013.

[8] J. J. Liu, X. Y. Wu, H. L. Lul et al., "Anti-proliferation effect of oridonin on Hl-60 cells and its mechanism," Chinese Medical Sciences Journal, vol. 19, no. 2, pp. 134-137, 2004.

[9] T.-C. Hsieh, E. K. Wijeratne, J.-Y. Liang, A. L. Gunatilaka, and J. M. Wu, "Differential control of growth, cell cycle progression, and expression of NF- $\kappa \mathrm{B}$ in human breast cancer cells MCF7, MCF-10A, and MDA-MB-231 by ponicidin and oridonin, diterpenoids from the Chinese herb Rabdosia rubescens," Biochemical and Biophysical Research Communications, vol. 337, no. 1, pp. 224-231, 2005.

[10] H.-Z. Hu, Y.-B. Yang, X.-D. Xu et al., "Oridonin induces apoptosis via PI3K/Akt pathway in cervical carcinoma Hela cell line," Acta Pharmacologica Sinica, vol. 28, no. 11, pp. 1819-1826, 2007.
[11] N. Kang, J.-H. Zhang, F. Qiu, S.-I. Tashiro, S. Onodera, and T. Ikejima, "Inhibition of EGFR signaling augments oridonininduced apoptosis in human laryngeal cancer cells via enhancing oxidative stress coincident with activation of both the intrinsic and extrinsic apoptotic pathways," Cancer Letters, vol. 294, no. 2, pp. 147-158, 2010.

[12] L. C. Meade-Tollin, E. M. K. Wijeratne, D. Cooper et al., "Ponicidin and oridonin are responsible for the antiangiogenic activity of Rabdosia rubescens, a constituent of the herbal supplement PC SPES," Journal of Natural Products, vol. 67, no. 1, pp. 2-4, 2004.

[13] J. Huang, L. Wu, S.-I. Tashiro, S. Onodera, and T. Ikejima, "Reactive oxygen species mediate oridonin-induced HepG2 apoptosis through p53, MAPK, and mitochondrial signaling pathways," Journal of Pharmacological Sciences, vol. 107, no. 4, pp. 370-379, 2008.

[14] Y. Zhang, Y. Wu, D. Wu, S.-I. Tashiro, S. Onodera, and T. Ikejima, "NF- $\kappa$ b facilitates oridonin-induced apoptosis and autophagy in HT1080 cells through a p53-mediated pathway," Archives of Biochemistry and Biophysics, vol. 489, no. 1-2, pp. 2533, 2009.

[15] A. Falamarzian and A. Lavasanifar, "Optimization of the hydrophobic domain in poly(ethylene oxide)-poly(eopencaprolactone) based nano-carriers for the solubilization and delivery of Amphotericin B," Colloids and Surfaces B: Biointerfaces, vol. 81, no. 1, pp. 313-320, 2010.

[16] E. H. Gokce, E. Korkmaz, E. Dellera et al., "Resveratrol-loaded solid lipid nanoparticles versus nanostructured lipid carriers: evaluation of antioxidant potential for dermal applications," International Journal of Nanomedicine, vol. 7, pp. 1841-1850, 2012.

[17] S. Wang, T. Chen, R. Chen, Y. Hu, M. Chen, and Y. Wang, "Emodin loaded solid lipid nanoparticles: preparation, characterization and antitumor activity studies," International Journal of Pharmaceutics, vol. 430, no. 1-2, pp. 238-246, 2012.

[18] R. S. Ray, B. Rana, B. Swami, V. Venu, and M. Chatterjee, "Vanadium mediated apoptosis and cell cycle arrest in MCF7 cell line," Chemico-Biological Interactions, vol. 163, no. 3, pp. 239-247, 2006. 

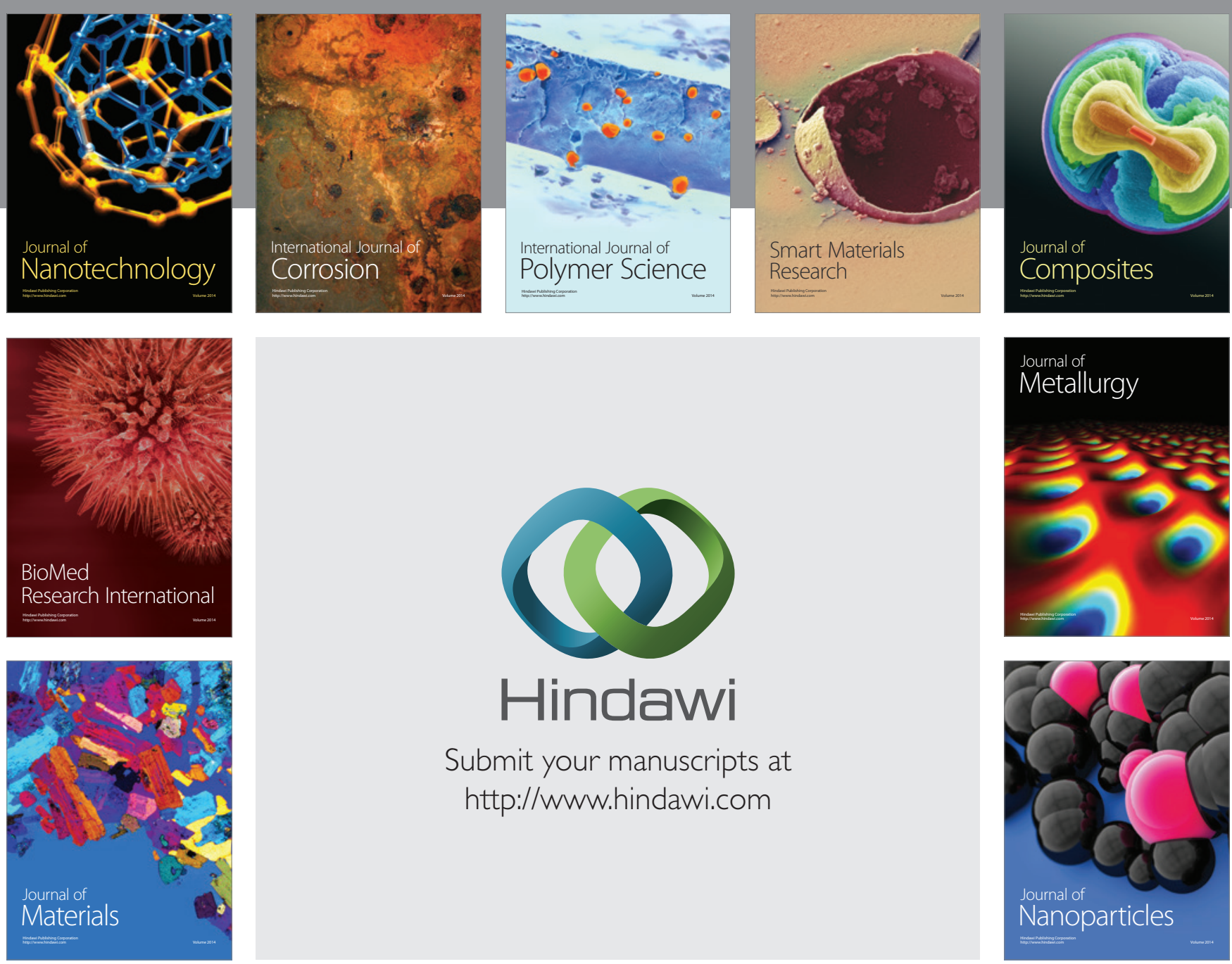

Submit your manuscripts at http://www.hindawi.com
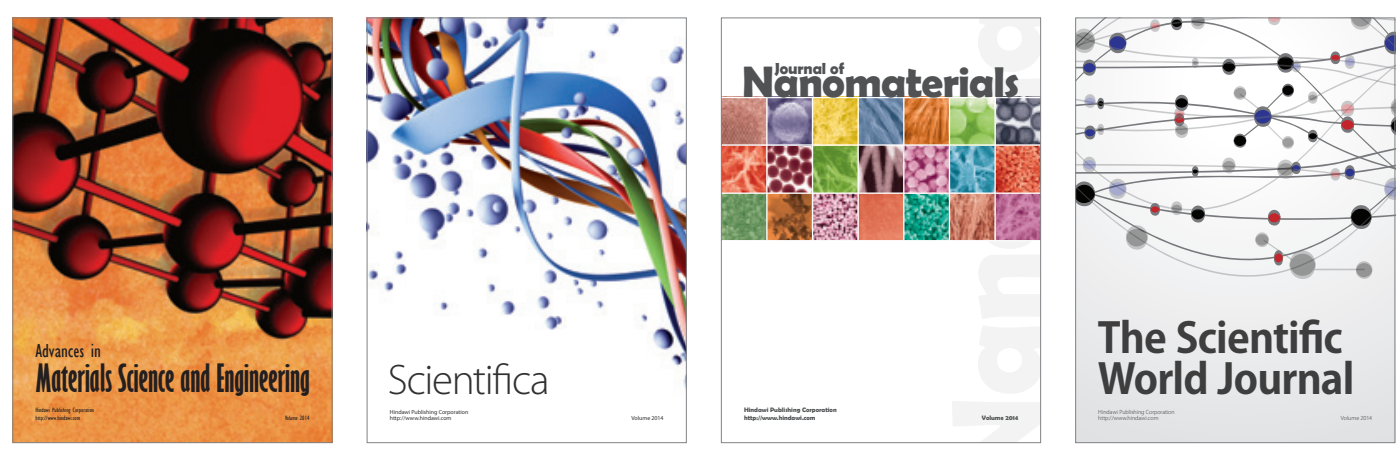

\section{The Scientific World Journal}
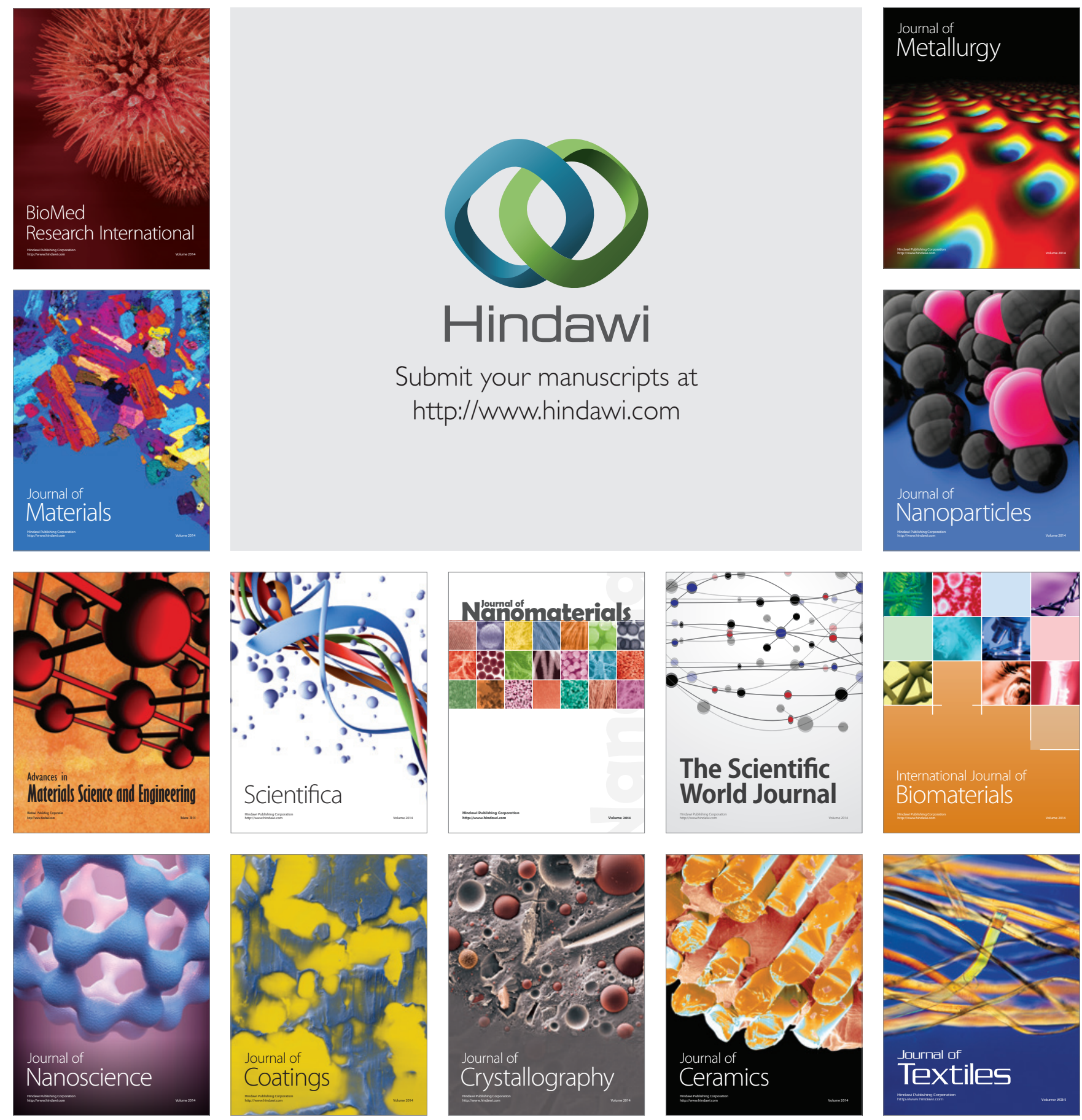